\title{
lúri Lotman e a Escola de Tártu-Moscou
}

\author{
Ekaterina Volkova Américo
}

Resumo: Objetivamos descrever a atuação de lúri Lotman na qualidade de iniciador e um dos participantes de destaque da Escola Semiótica de Tártu-Moscou (1960-1980). O trabalho conta com documentos e fotografias do arquivo pessoal de Serguei Nekliúdov, também integrante da Escola, que ilustram as atividades dos semioticistas no contexto do sistema soviético. Abordamos ainda alguns fundamentos do pensamento da Escola de Tártu-Moscou e de Lotman, como a noção de "sistemas modelizantes secundários" e a lógica das oposições binárias.

Palavras-chave: lúri Lotman; Escola Semiótica de Tártu-Moscou; semiótica russa; semiótica da cultura; cultura e literatura russa.

Abstract: Yuri Lotman and the Tartu-Moscow School - We aim to describe Yuri Lotman's role as an instigator and as a key member of the Tartu-Moscow School (1960-1980). This paper presents documents and photographs from Sergei Nekliúdov's personal archive, who was also a member of this school. This archive shows some activities of these semioticians in the context of the Soviet system. We also approach some of the theoretical grounds of the TartuMoscow School and Lotman, such as the notion of "secondary modelling systems" and the logic of binary oppositions.

Keywords: Yuri Lotman; Tartu-Moscow Semiotic School; russian semiotics; semiotics of culture; russian culture and literature.

\section{Introdução}

O presente artigo visa abordar o período entre os anos 1960-1980, em que surgiu e se desenvolveu o fenômeno da "Escola Semiótica de Tártu-Moscou", iniciada e liderada por lúri Lotman. Ao se falar da Escola semiótica russa, é necessário observar primeiramente que, apesar de ter sido fundada por esse expoente semioticista, ela contou com a participação de muitos autores de renome, tais como: Vladímir Toporov, Borís Uspiénski, Viatcheslav Ivánov, Eleazar Meletínski e Serguei Nekliúdov, entre outros. 
Trata-se, portanto, de uma interação constante entre especialistas de diferentes áreas, como linguística, estudos literários, folclorística, culturologia e até mesmo das ciências exatas (por exemplo, a contribuição extremamente relevante de Vladímir Uspiénski, matemático e linguista, dentre outros).

Neste artigo procuramos recuperar o contexto histórico-cultural que moldou os rumos da Escola Tártu-Moscou, ${ }^{1}$ baseando-se nas memórias de Lótman e de outros integrantes sobre aquele período, bem como nos documentos e fotografias pessoais de Serguei Nekliúdov, um dos maiores especialistas em semiótica do folclore.

A bibliografia brasileira dedicada à Escola inclui a coletânea Semiótica russa (SCHNAIDERMAN, 1979) com os ensaios mais importantes dos semioticistas soviéticos; o livro Escola de Semiótica - A Experiência de Tártu-Moscou para o estudo da Cultura (MACHADO, 2003), com uma descrição detalhada dos conceitos da Escola, bem como os trabalhos de Jerusa Pires Ferreira, que enfocam principalmente a correlação entre cultura e memória na obra lotmaniana, como ocorre no texto "Cultura é memória" (2004).

\section{As origens da Escola}

Além da forte influência das ideias de Ferdinand de Saussure e do estruturalismo ocidental, a atividade da Escola Semiótica de Tártu-Moscou também se origina nos trabalhos dos estudiosos russos e, nesse sentido, entre os seus principais precursores estão o linguista e estudioso de literatura Aleksandr Potebniá (1835-1891) e o historiador da literatura Aleksandr Vesselóvski (1838-1906). A análise dos processos linguísticos e literários, feita por ambos os pesquisadores sob um prisma teórico e histórico, permite chamá-los de fundadores dos estudos culturais, literários, linguísticos e semióticos na Rússia.

Já no século XX, entre os antecessores da semiótica soviética estão os formalistas que, opondo-se à linha tradicional dos estudos literários (representada por método histórico, isto é, diacrônico), defendiam o emprego exclusivo do método sincrônico. Porém, ambas as abordagens (a sincrônica e a diacrônica) parecem confluir na obra do formalista lúri Tyniánov (1894-1943).

Em seus textos "O fato literário" (1924) e "Da evolução literária" (1927) são apresentadas as leis que determinam a sucessão de gêneros literários na história da literatura mundial. A mesma combinação metodológica ocorre no livro Morfologia do conto maravilhoso (1928), de Vladímir Propp: por um lado, o método sincrônico permite definir as principais funções do conto maravilhoso, mas, por outro, trata-se da sua análise diacrônica no contexto do desenvolvimento histórico. Como resultado da fusão entre essas duas tendências, surgiu a abordagem estrutural-semiótica, amplamente aplicada pelos semioticistas soviéticos (NEKLIÚDOV, 2006).

1 De agora em diante Escola. 
Os anos 1960, período do início das atividades da Escola, foram marcados por um desenvolvimento intenso (às vezes também chamado de "superação") do estruturalismo que, de área estritamente linguística, passou para as ciências humanas em geral. Foi nesse contexto que, em 1964, começaram a ser publicadas na Universidade de Tártu as primeiras edições das coletâneas Trabalhos sobre os sistemas sígnicos, que reuniam os textos dos pesquisadores que posteriormente formaram a Escola.

Assim como outros estudiosos daquele período, Lotman também foi muito influenciado pelo estruturalismo e, como consequência disso, na primeira edição dos Trabalhos sobre os sistemas sígnicos, foi publicado o seu livro Curso de poética estrutural. Desse modo, nas coletâneas e em outras obras dos representantes da Escola, consolidou-se o método estrutural-semiótico.

Inicialmente aplicada por Lotman à literatura, nos anos a seguir, a abordagem passou a abarcar os problemas culturais em geral. No centro dela encontrava-se o modelo binário, herdado de Saussure, a partir do qual os semioticistas destacavam as oposições binárias, presentes na cultura russa e mundial.

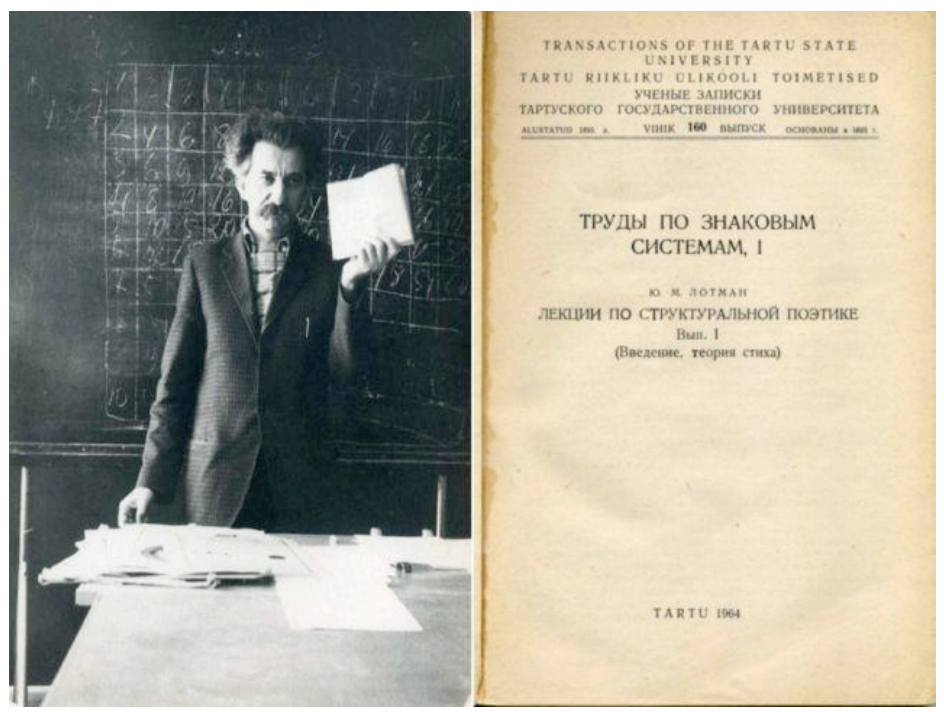

Fig. 1. lúri Lotman com a primeira edição do seu livro Curso de poética estrutural, publicado na coletânea Trabalhos sobre os sistemas sígnicos, em 1964. Fonte: Foto do arquivo pessoal de Serguei Nekliúdov.

\section{A Escola}

Provavelmente, um dos traços mais peculiares da Escola foi o fato de que ela era formada por dois centros científicos: um em Moscou, do qual participaram os irmãos Boris e Vladímir Uspiénski, Vladímir Toporov, Viatcheslav Vsiévolodovitch Ivánov, e outro 
em Tártu, Estônia, composto principalmente por lúri Lotman, Zara Mints e Borís Egórov. Até o próprio título "Escola de Tártu-Moscou" foi questionado várias vezes, em especial por seus representantes de Moscou, que sugeriam "Escola de Moscou-Tártu".

Recorreremos às memórias de Lotman sobre esse período:

Naqueles anos, a criação científica se desenvolvia com uma rapidez excepcional, principalmente em Moscou e Leningrado. Em Moscou, surgiu ao redor de Viatcheslav Vsiévolodovitch Ivánov um círculo de pesquisadores jovens e extremamente talentosos. Era uma verdadeira explosão, comparável apenas às explosões culturais da Renascença ou do século XVIII, e o seu epicentro não era a cultura russa e sim a indologia, os estudos orientais em geral, a cultura medieval. Uma união científica era necessária, porém não era fácil conseguir isso. Os centros de Tártu e de Moscou partiam de pontos diferentes e avançavam por caminhos bastante diferentes. O centro de Moscou em geral baseava-se na experiência dos estudos linguísticos e nos estudos das formas arcaicas da cultura. Mais do que isso, se o folclore e os tipos literários, como a novela policial, ou seja, gêneros orientados para a tradição, para as linguagens fechadas, eram considerados um território natural da semiótica, a possibilidade de aplicação dos métodos semióticos a sistemas complexos e não fechados, como a arte moderna, era inteiramente questionada (LOTMAN, 1995, p. 47-48). ${ }^{2}$

Uspiénski (1994, p. 266-269) igualmente segrega duas tendências dentro da Escola: a linguística, representada por Moscou, e a de estudos literários, orientada para a análise de texto, localizada em Tártu. Esse modelo binário, que também era um dos principais objetos da análise dos semioticistas russos, foi herdado dos antecessores da Escola: a OPOIAZ (Sociedade de Estudos de Linguagem Poética), em Petrogrado (1916-1925), e o Círculo Linguístico de Moscou (1915-1924), cujos conceitos principais formaram depois a base do Círculo Linguístico de Praga (1926-1953) e da LEF, Frente de Esquerda das Artes (1922-1928), bem como do futurismo.

Segundo Uspiénski, a existência desses dois centros dentro na Escola reflete o caráter bicêntrico próprio da cultura russa em geral:

[...] eu gostaria de sublinhar que a presença de dois centros culturais, a bipolaridade, ou seja, a coexistência de duas tradições, que ascende a dois centros culturais, em geral é característica da cultura russa e determina a sua especificidade tipológica. De fato, um olhar mais geral sobre a história russa permite ver nela a essencial e contínua coexistência de dois centros culturais que estão em oposição e partem um do outro: centros com tradições culturais claramente diferentes (ibid., p. 268).

2 Os trechos citados a partir do russo foram traduzidos pela autora. 
O surgimento da Escola foi possibilitado pelo abrandamento do regime soviético, que, naquela época, passava por um período conhecido como "degelo", e pela posição afastada e, portanto, mais independente, da Universidade de Tártu, na qual lecionava Lotman. Foi nesse contexto que os intelectuais encontraram um refúgio do controle onipresente do poder oficial em assuntos muito distantes dos temas políticos:

Já no início dos anos 1950 as repúblicas bálticas, em geral, a Estônia e Tártu, em grau ainda maior, atraíram certa parte da intelliguéntsia russa. [...] Lá se reuniam aqueles para os quais o "degelo" abrira a possibilidade de emancipação, se não das instituições oficiais, então, pelo menos, do sistema oficialmente sancionado de valores intelectuais. [...] O próprio fato de que esse mundo especial existia dava a sensação de uma independência interior, de escape de um ambiente instável para um espaço espiritual e protegido, que representava uma necessidade vital nas condições do degelo intelectual inseguro e instável vigente naqueles anos (GASPÁROV, 1994, p. 280).

Além do distanciamento por meio da posição apolítica, os membros da Escola manifestavam a sua discordância em relação ao regime escolhendo para a sua análise épocas históricas ou assuntos que induzissem reflexões sobre a situação presente do país:

A semiótica soviética representa um caso característico de um projeto científico, que surgiu e se moldou nos limites de um rígido controle ideológico sobre a produção do conhecimento histórico, e não apenas resolvia as suas tarefas disciplinares, mas também era um meio de resistência intelectual aos mitos históricos oficiais, tornando-se uma forma de desmistificação direta ou oculta. Além disso, por trás da prática dos estudos semióticos na União Soviética estavam os mecanismos mais complexos e ambíguos. A semiótica soviética usava determinadas épocas não apenas como um objeto de análise histórica, mas também como um meio de reflexão sobre o seu próprio contexto histórico [...] (KALÍNIN, 2009, s/p).

Portanto, a semiótica soviética ia muito além de objetivos puramente científicos, pois a semiotização da realidade pode ser compreendida como uma tentativa de questioná-la e admitir a possibilidade de outras leituras, isto é, de uma pluralidade de opiniões:

[...] o vínculo do projeto semiótico com o contexto histórico ou político que o rodeava não se esgota com os paralelos ocultos entre a época estudada e a contemporaneidade. O próprio olhar para a realidade como um conjunto total de signos pode ser visto como uma reação a um determinado trauma histórico. Nesse sentido, a semioticização total da realidade, realizada nos limites do método semiótico, é uma tentativa de opor-se à entropia da informação dada pela reprodução insistente da ideologia dominante e dos mitos culturais regentes (Ibid., s/p). 
Como o termo "semiótica" não era bem visto na União Soviética por estar ligado aos estudos semióticos do Ocidente, o matemático e linguista Vladímir Uspíenski sugeriu a denominação de "sistemas modelizantes secundários" (vtorítchnyie modelíruiuschie sistiémy), o que, por um lado, era uma substituição digna do termo considerado "perigoso" e, por outro, era uma palavra científica e complicada o suficiente para confundir os informantes do governo que provavelmente estavam inseridos nas atividades da Escola. Eis como o próprio autor dessa denominação a descreve:

\begin{abstract}
A meu ver, o nome possuía as seguintes qualidades essenciais: 1) soava de modo muito científico; 2) era totalmente incompreensível; 3) contudo, no caso de uma grande necessidade, podia ser explicado: os sistemas primários que modelam a realidade são as línguas naturais, enquanto todas os outros, construídos sobre eles, são secundários (USPIÉNSKI, 1995, s/p).
\end{abstract}

Dessa forma, os sistemas modelizantes secundários são os sistemas que foram construídos sobre a língua natural e, portanto, são secundários em relação a ela. Eles também podem ser chamados de sistemas semióticos ou de linguagens culturais. O termo, que nasceu como um artifício e com o objetivo de ser incompreensível (e aqui encontramos mais uma correlação com os futuristas russos, criadores da linguagem transmental, záum), foi levado por Lotman e outros semioticistas russos a sério.

Eles desenvolveram a ideia de texto da cultura como um sistema secundário, construído com base em um sistema primário, a língua. Em geral, um dos traços fundamentais da Escola foi a ampliação dos conceitos linguísticos, aplicados aos fenômenos mais variados. Nas palavras de Schnaiderman (1997, p. 142):

Quando aquele grupo surgiu, no limiar dos anos 60, ele se mostrou preocupado com a visão global da cultura. Ao mesmo tempo, porém, se atinha à noção de que os diferentes ramos do saber constituiriam os "sistemas modelizantes secundários", isto é, secundários em relação à linguagem verbal.

Como a Escola atraía estudiosos de diversos áreas - mitologia, literatura, pintura, cinema, etc. -, a interdisciplinaridade se tornou um dos seus traços mais marcantes. A própria posição fronteiriça da cidade de Tártu, entre a então União Soviética e o Ocidente, abria possibilidades para inúmeros diálogos interculturais:

O encontro direto de várias escolas e, mais do que isso, de vários estudiosos que se diferenciavam por particularidades científicas individuais, áreas de experiência científica, maior ou menor inclinação para a tradição ou a arte individual, apresentou um resultado excepcionalmente frutífero e o desenvolvimento posterior dos estudos semióticos em muito se deve a essa feliz combinação (LOTMAN, 1995, p. 48). 
O caráter enriquecedor que se deve à junção das duas escolas, a de Tártu e a de Moscou, foi destacado também por Borís Uspiénski:

Dessa forma, a Escola Semiótica de Tártu-Moscou reúne duas tradições: a linguística de Moscou e a de estudos literários de Leningrado, que enriquecem mutuamente. Tal simbiose de tradições foi extremamente frutífera para cada uma das partes (USPIÉNSKI, 1994, p. 268).

Entretanto, a natureza ocasional da formação da Escola teve seu papel negativo: algumas áreas de estudo ficaram fora do seu âmbito ou, então, foram prejudicadas. Como observa mais um de seus membros, lu. Lévin:

É verdade que entre os participantes das escolas de Tártu havia representantes de muitas profissões das humanidades. Porém, é essencial que predominassem três delas: a linguística, os estudos da literatura (russos) e a indologia (mitologia e folclore, em sua maioria, serviam de ocupação secundária), e, justamente, os representantes dessas disciplinas predeterminaram as principais tendências dos estudos (por exemplo, a cultura russa dos séculos XVIII - XIX, o simbolismo, o acmeísmo, a indologia, bem como os estudos do mito) e a sua ênfase metodológica (que partia principalmente do estruturalismo linguístico). [...] Por outro lado, o caráter ocasional de formação do "corpo" da escola resultou na ausência, nela, por exemplo, de sinólogos, sociólogos, advogados, e todas esses campos de pesquisa não entraram no círculo dos estudos semióticos (LIÉVIN, 1994, p. 310).

No que diz respeito ao simbolismo, a partir da citação acima, pode parecer que esse tema também foi escolhido aleatoriamente. No entanto, o simbolismo, como corrente literária da literatura russa do limiar dos séculos XIX-XX, é um dos responsáveis diretos pelo surgimento e desenvolvimento da semiótica na União Soviética, pois o símbolo poetizado e analisado pelos simbolistas tornou-se o objeto principal dos estudos semióticos. Isso se torna especialmente claro se lembrarmos, por exemplo, do seguinte trecho do ensaio de Viatcheslav Ivánov (1866-1949), um dos principais poetas e teóricos do simbolismo russo:

O símbolo é um sinal ou uma assinalação. Aquilo que ele significa ou assinala não é uma ideia determinada. Não se pode dizer que a serpente, como símbolo, significa somente "o sacrifício do sofrimento expiatório". Ou seja, o símbolo é um simples hieróglifo, e a combinação de vários símbolos é uma alegoria com imagens, uma mensagem cifrada que pode ser lida por meio da chave encontrada desse código. Se o símbolo é um hieróglifo misterioso, ele tem muitos significados e sentidos. Em várias esferas da consciência, o mesmo símbolo adquire vários significados. Assim, a serpente tem um significado de assinalação em relação à Terra e, ao mesmo tempo, à encarnação, ao sexo, à morte, à visão e ao conhecimento, à tentação e à consagração (IVÁNOV, 2005, p. 197). 
Portanto, para os simbolistas, o símbolo não era apenas um meio de expressão, mas também assunto de pesquisas teóricas, e nesse sentido eles podem ser apontados como precursores indiscutíveis da semiótica russa.

Porém, voltaremos às atividades da Escola. Com o objetivo de oferecer aos participantes uma oportunidade de se encontrarem pessoalmente e discutirem os problemas mais relevantes, foram organizadas as Escolas de Verão. Essas reuniões ocorreram em cinco oportunidades: em 1964, 1966 e 1968, na base esportiva da Universidade de Tártu, que se localizava em Kääriku, pequeno vilarejo estoniano, e, em 1970 e 1974, em Tártu.

As condições da base esportiva eram muito simples: a maioria dos quartos tinha apenas beliches, mas isso não afugentava os participantes. Assim, o renomado folclorista Piotr Bogatyriov, apesar de sua idade avançada, não deixava de integrar essas reuniões e, em 1966, Roman Jakobson fez parte da II Escola de Verão, durante a qual foi celebrado o seu aniversário de 70 anos.

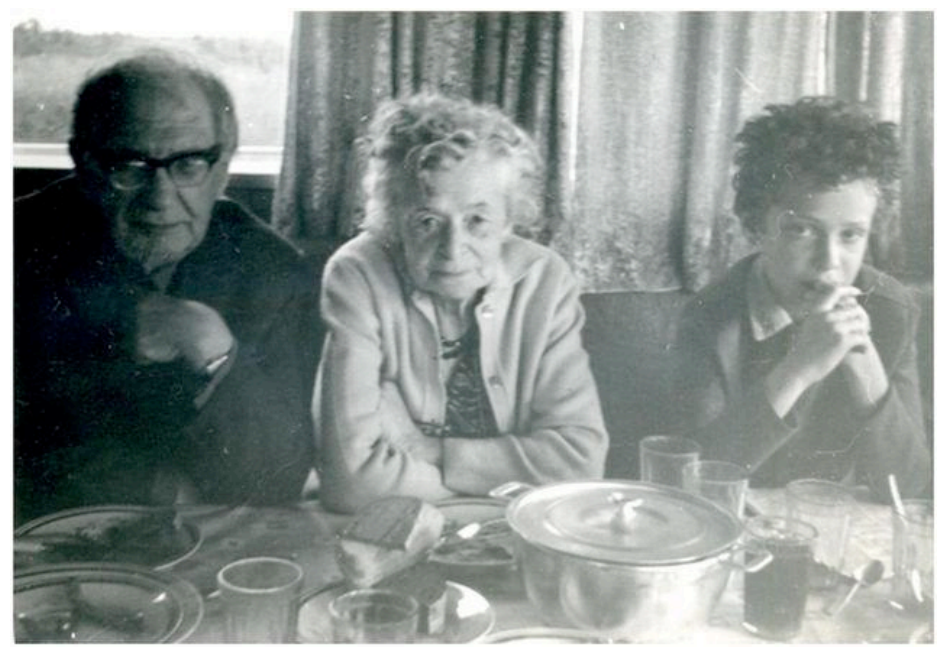

Fig.2. Piotr Bogatyriov com a esposa e o neto durante a IV Escola de verão, em 1970.

Fonte: Foto do arquivo pessoal de Serguei Nekliúdov.

Mikhail Bakhtin sempre era convidado a participar das Escolas, mas como suas condições físicas não permitiam que ele enfrentasse a viagem e, devido à simplicidade do alojamento em Kääriku, o convite não pôde ser aceito. Entretanto, como lembra Boris Uspiénski, Bakhtin "se interessava ativamente por nossos trabalhos" (1994, p. 268).

Abaixo pode ser visto um dos convites para participar da III Escola de Verão de 1968, gentilmente concedido pelo destinatário, Serguei Nekliúdov: 


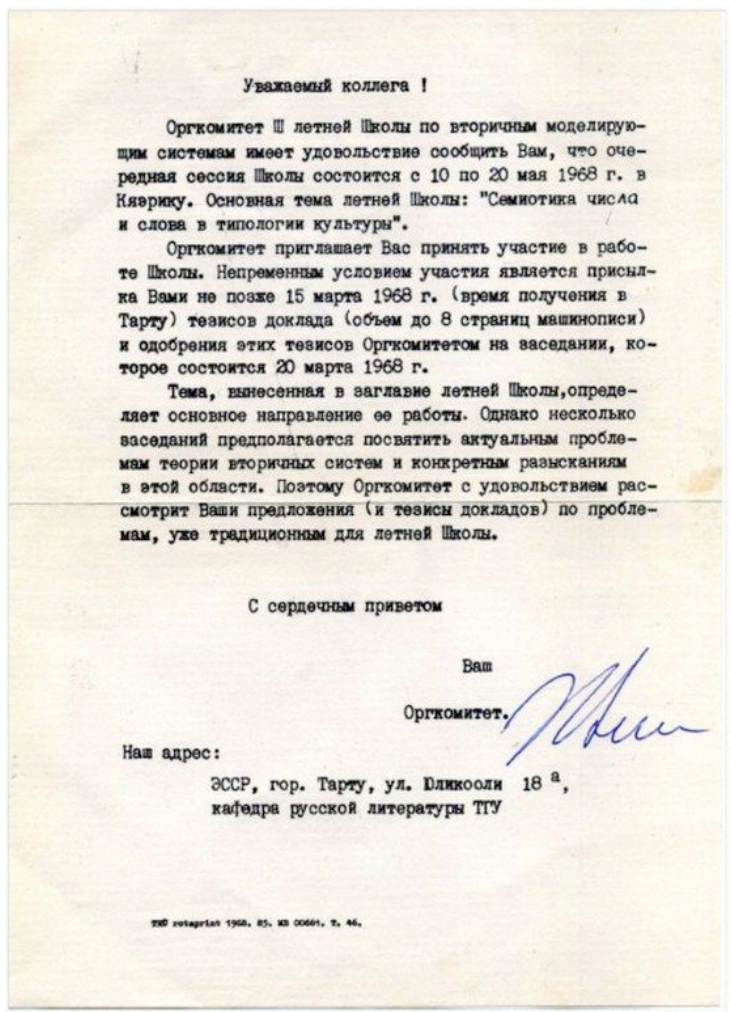

Fig. 3. Convite para a III Escola de Verão de 1968. Fonte: Arquivo pessoal de Serguei Nekliúdov.

\section{Diz o convite:}

\section{“Prezado colega!}

O Comitê Organizacional da III Escola de Verão sobre os sistemas modelizantes secundários tem o prazer de Ihe comunicar que a próxima sessão da Escola acontecerá de 10 a 20 de maio de 1968, em Kääriku. O tema principal da Escola de Verão será: "A semiótica do número e da palavra na tipologia da cultura".

O Comitê Organizacional convida o Senhor a integrar o trabalho da Escola. Para participar, é imprescindível enviar até o dia 15 de março de 1968 (data de recebimento em Tártu) as teses da comunicação (até 8 páginas digitadas à maquina), cuja aprovação será feita durante a reunião do Comitê Organizacional, que ocorrerá em 20 de março de 1968.

O tema proposto para a Escola de Verão deve nortear a principal direção do seu trabalho. Entretanto, planejamos dedicar algumas reuniões aos problemas atuais da teoria dos sistemas secundários e às pesquisas concretas nessa área. Portanto, o Comitê Organizacional analisará com prazer as suas propostas (e teses de 
apresentação) relacionadas aos problemas que já se tornaram tradicionais para a Escola de Verão.

Cordialmente,

Seu Comitê Organizacional"

Apresentamos, na sequência, o "Bilhete de participante da III Escola de Verão sobre os sistemas modelizantes secundários":

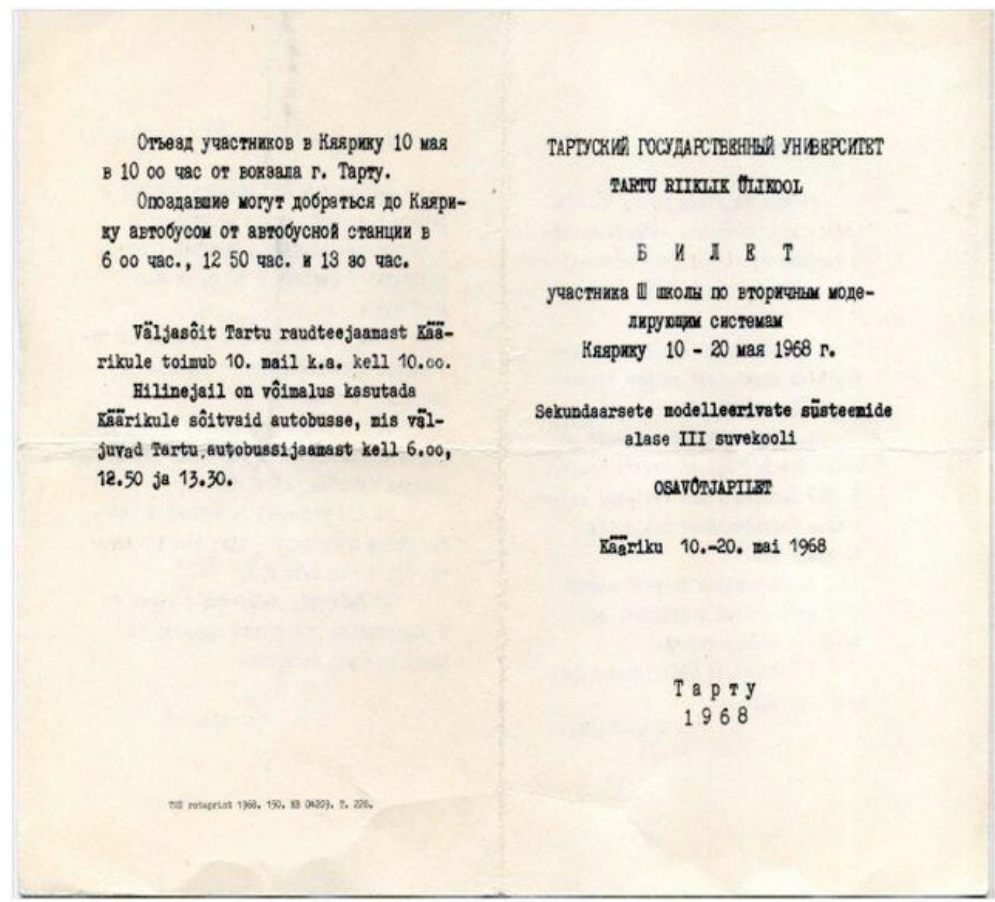

Fig. 4. Bilhete de participante da III Escola de Verão sobre os sistemas modelizantes secundários (frente). Fonte: Arquivo pessoal de Serguei Nekliúdov. 


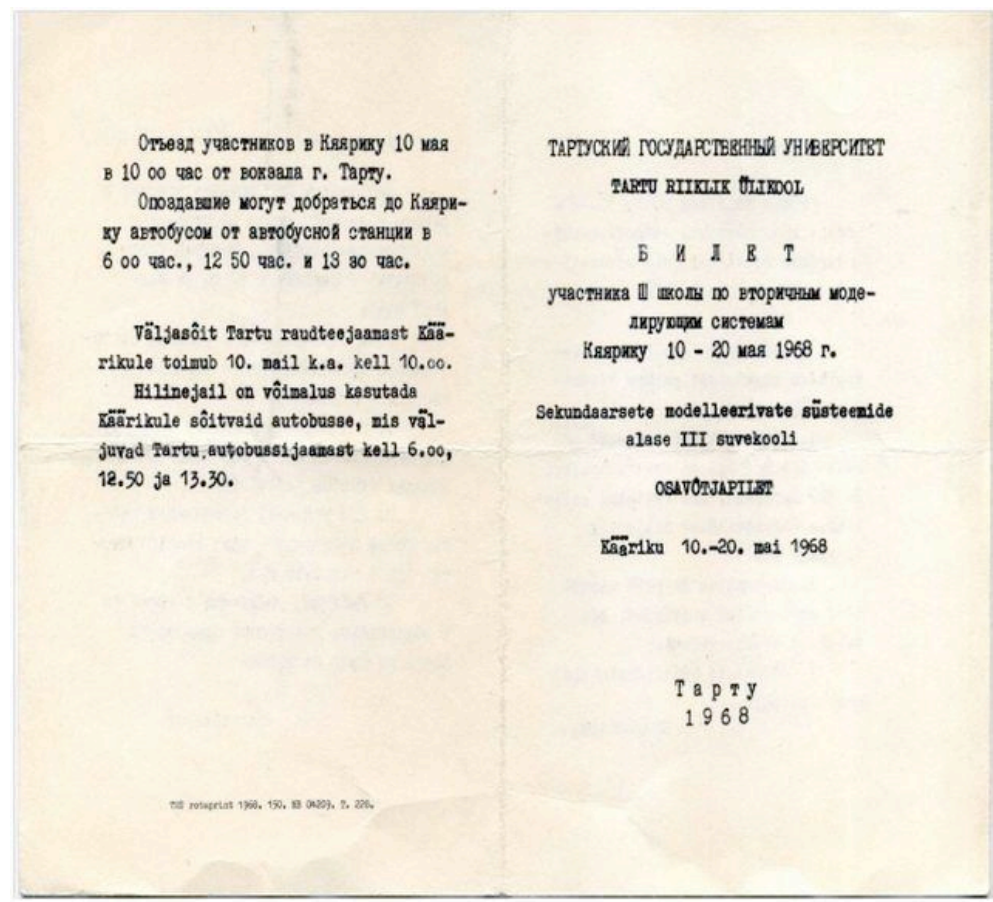

Fig. 5. Bilhete de participante da III Escola de Verão sobre os sistemas modelizantes secundários (verso). Fonte: Arquivo pessoal de Serguei Nekliúdov.

O que chama a atenção nesse bilhete é a segunda parte, na qual consta:

[...] Devido a circunstâncias excepcionalmente difíceis de caráter organizacional, devemos lembrar que:

1. A participação nas sessões será permitida apenas aos participantes portadores do bilhete pessoal.

Certamente, essa cláusula, que remete ao caráter hermético da Escola, foi incluída na esperança de evitar convidados indesejáveis e até "perigosos", enviados pelo governo.

A última reunião das Escolas de Verão ocorreu em 1986. Entre as memórias dos participantes que também representavam o núcleo da Escola Semiótica, o mais polêmico foi o ensaio de Borís Gaspárov, A escola de Tártu dos anos 1960 como um fenômeno semiótico, escrito post factum, em 1989. Nele, o autor apresenta em um quadro os traços mais característicos da Escola, quase sem citar nomes nem trabalhos concretos dos seus participantes. De acordo com Gaspárov, não apenas o conceito de "sistemas modelizantes secundários" era um pouco "transmental" e objetivava confundir um observador externo, como toda a linguagem utilizada pelos semioticistas também o era: 
O caráter hermético da sociedade científica era mantido também por meio da linguagem científica esotérica comum a esse círculo. A língua que os pesquisadores de Tártu falavam e na qual escreviam era repleta de uma terminologia imanente aos estudos semióticos e não utilizada fora dos seus limites. Muitas expressões dessa linguagem "semiótica" específica foram criadas pelos membros do grupo e utilizadas excepcionalmente na comunicação com os outros membros. Várias palavras representavam uma transliteração direta de termos estrangeiros, não utilizados na tradição científica russa, fato que contribuía à linguagem esotérica um tom "tipicamente" ocidental (GASPÁROV, 1994, p. 284).

A Escola tinha adeptos em várias universidades soviéticas e gozava de uma influência considerável sobre o universo acadêmico, mas, apesar disso, de certo modo era uma fuga da realidade soviética e os seus participantes formavam uma sociedade fechada com seu próprio código de conduta, sua linguagem e círculo de iniciados:

Em compensação, para os "iniciados", a forma das Escolas de Verão possuía grandes vantagens. Alguns dias de vida em conjunto, em isolamento do mundo externo, criavam um ambiente intelectual único pelo seu caráter intensivo. O círculo que se reunia em uma base fora da cidade (algumas dezenas de pessoas) representava um ambiente "puro", separado da contaminação do mundo externo (lbid., p. 283).

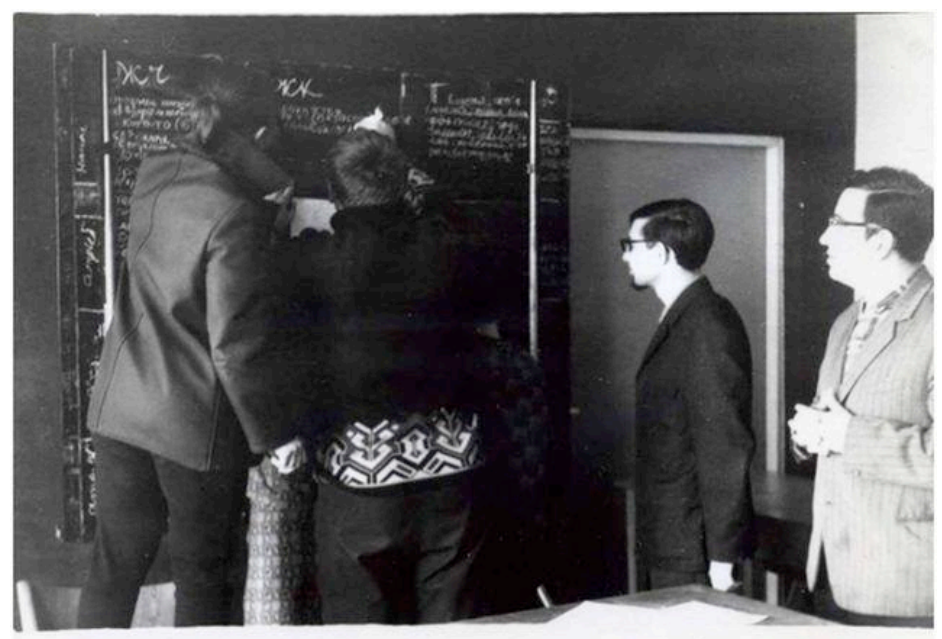

Fig. 6. Os preparativos para a reunião da III Escola de verão de 1968. Fonte: Arquivo pessoal de Serguei Nekliúdov. 


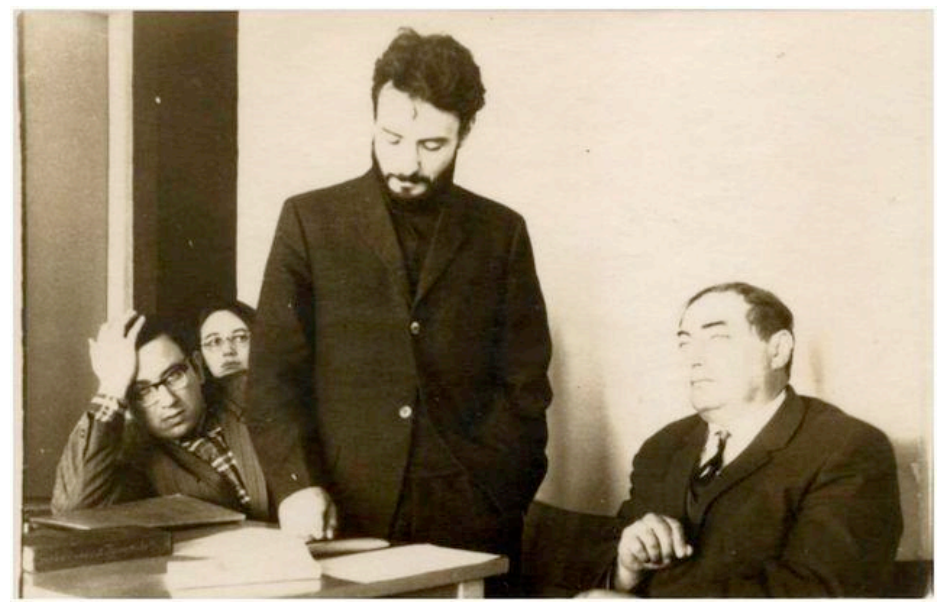

Fig. 7. Palestra de Serguei Nekliúdov sobre a estrutura do conto maravilhoso durante a III Escola de verão, em 1968. Da esquerda para a direita: D. Segal, E. Nóvik, S. Nekliúdov, E. Meletínski. Fonte: arquivo pessoal de Serguei Nekliúdov.

Porém, na opinião de lúri Lotman, essa caracterização feita por Gaspárov representava apenas uma parte da verdade. Em suas pesquisas, os semióticos soviéticos queriam não apenas se alienar do mundo externo, mas transformar a realidade com a sua ajuda:

Nessa situação, formaram-se duas orientações culturais. A primeira, representada por Gaspárov, como uma continuação da tradição de Pasternak, de caráter enclausurado, era a tendência de "não abrir janelas". [...] Já no que se refere a Z. G. Mints, B. F. Egórov e a mim, nós nos tornamos iluministas por princípio, aspirávamos "semear a razão, o bem, o eterno" (LOTMAN, 1995, p. 49).

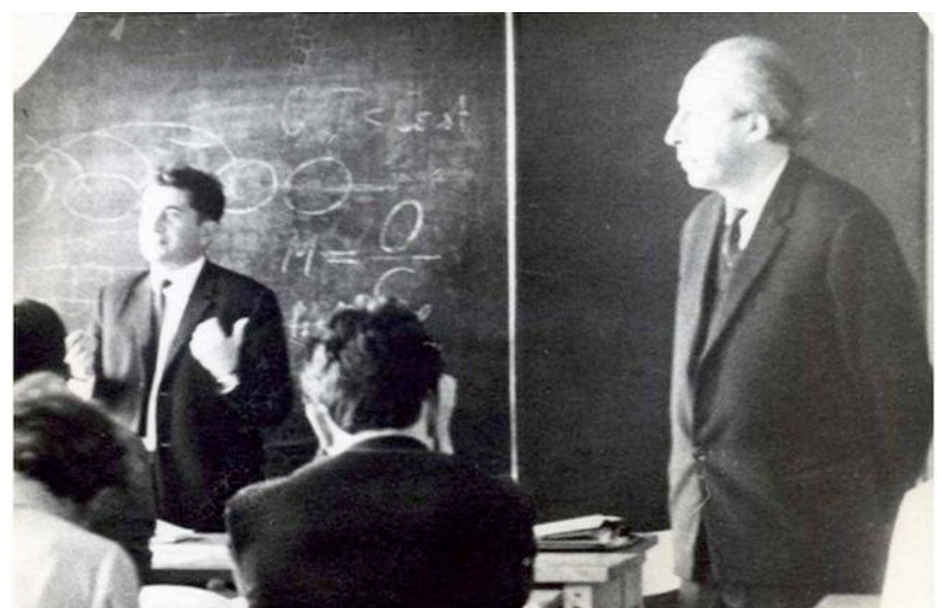

Fig. 8. III Escola de verão, agosto de 1968. Discussão sobre a comunicação de I. I. Riévzin (de pé, perto da lousa). De pé do lado direito: G. A. Lieskiss. Fonte: Arquivo pessoal de Serguei Nekliúdov. 
No trecho citado acima, Lotman se afasta da "orientação" de Gaspárov e chama-a de "tendência de não abrir janelas". Aqui necessitamos de algumas explicações: trata-se de um trecho da poesia de Boris Pasternak Ruptura (Razrýv), escrita em 1918, que termina da seguinte forma:

Nos dias de hoje até o ar exala morte;

Abrir uma janela é como abrir as veias. ${ }^{3}$

Os versos de Pasternak, é claro, remetem a outra época, provavelmente até mais conturbada do que a dos estudiosos de Tártu, porém transmitem muito bem o eterno dilema do intelectual russo entre fugir da realidade e fechar as janelas ou, ao contrário, abrir-se o máximo possível e "semear a razão, o bem, o eterno" e "criar a vida" de acordo com rigorosas normas morais: não apenas criá-la, como também transformá-la, iluminá-la. Gaspárov chama essa aspiração de "utopismo" e afirma que era um dos marcos distintivos da semiótica soviética:

De fato, a atividade da Escola Semiótica da década de 1960 continha traços claros do pensamento utópico. É possível destacar esses seus indícios como a aspiração a uma síntese absoluta na qual tudo e todos os tipos de fenômenos obtivessem uma legítima correlação; o pensamento totalizante, o predomínio do objetivo geral sobre os interesses particulares "empíricos", a sensação de tempo parado relacionada à globalidade do objetivo: dali em diante o avanço consistiria na realização do plano traçado até que ele fosse cumprido (GASPÁROV, 1994, p. 292).

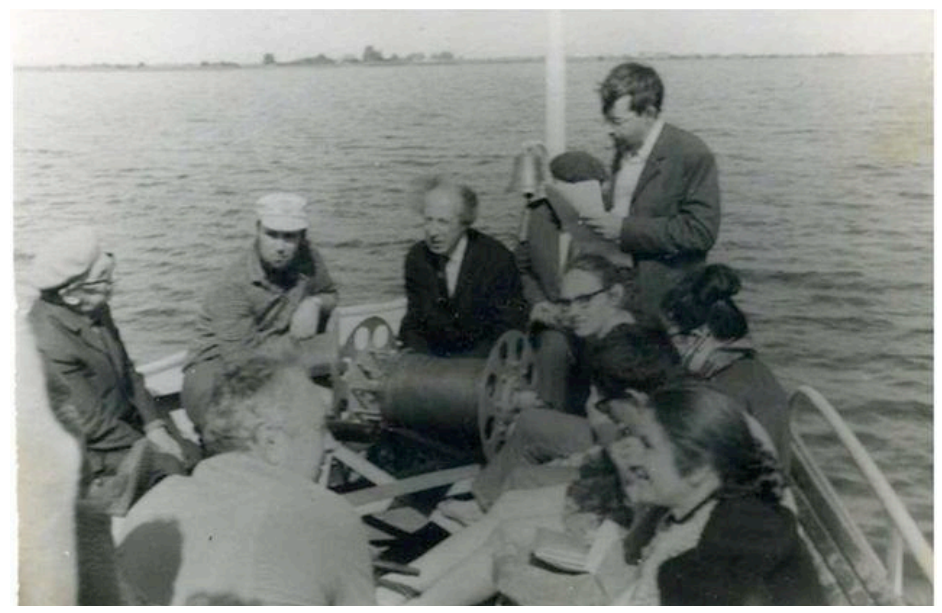

Fig. 9. Reunião no barco: IV Escola de verão, 1970.

Fonte: Arquivo pessoal de Serguei Nekliúdov.

3 Tradução nossa. Em russo: А в наши дни и воздух пахнет смертью;/Открыть окно, что жилы отворить. 
Recorrendo à terminologia de Eleazar Meletínski (1918-2005), mais um participante renomado da Escola, essa missão era bastante arquetípica: transformar o caos do mundo externo, ou seja, a sociedade soviética instável do período pós-stalinista, em uma ordem ideal através da sua leitura semiótica e do estabelecimento de suas leis. Essa visão cria uma ilusão de domínio sobre o caos e da possibilidade de vencê-lo. As fronteiras entre a pesquisa científica e a vida real deixam de existir:

Por fim, a totalidade do pensamento utópico leva à eliminação das fronteiras entre a criação artística ou científica e a "vida". A diferença essencial entre a construção da vida semiológica e, por exemplo, a dos simbolistas, consistia no fato de que o seu objeto não eram apenas os "textos" da vida como tal, e sim a língua por meio da qual ela pensava, expressava-se e interagia com o mundo externo (GASPÁROV, 1994, p. 292).

A evolução da ideia de transformação da vida através do processo criativo tem sua origem ainda no sentimentalismo e romantismo russo do início do século XIX, quando surgiu e foi desenvolvida a noção da incoerência trágica entre vida e arte. Retomada pelos poetas e escritores do século XX, ela também refletiu nas atividades da Escola:

\begin{abstract}
O caráter utópico da semiótica dos anos 1960 a aproxima de muitos movimentos artísticos e intelectuais do início do século: do simbolismo até as atividades da OPOIAZ. Nisso, é claro, não há nada de surpreendente já que a poética estrutural está relacionada geneticamente com as teorias simbolistas e pós-simbolistas da palavra poética, com a poética da escola formal e da linguística estrutural. Podemos apenas destacar que, em comparação com os seus antepassados, a escola semiótica do período do "degelo" diferenciava-se pela tendência muito mais radical de fechamento e de introspecção (Ibid., p. 292-293).
\end{abstract}

A característica especial dessas duas últimas etapas, ou seja, formalismo e estruturalismo, é o fato de elas representarem um meio inteiramente científico das possibilidades de transfiguração da vida real. Já a obra de Lotman e dos semioticistas soviéticos encontrava-se, por um lado, fortemente influenciada por essa ideia messiânica, e, por outro, tinha plena consciência dessa influência, estudando e analisado-a em todos os seus aspectos.

Se os anos 1960 foram marcados pela forte ligação dos estudos da Escola semiótica com os conceitos linguísticos, na década seguinte, os seus horizontes se ampliam de forma significativa. A semiótica como ciência emancipa-se e enfoca a cultura.

\title{
$O$ final aberto e a herança
}

Tanto Uspíenski, quanto Gaspárov terminam a descrição cronológica das atividades da Escola com a chegada dos anos 1970. Nessa época, foi concluída a primeira etapa de 
desenvolvimento da Escola, marcada por buscas intensas, e ela se transformou em algo diferente: não era mais uma sociedade secreta de escolhidos que se encontravam em oposição ao mundo externo. A Escola deixou de ser tão coesa, e cada um dos participantes seguiu o seu rumo de forma mais independente:

Nos anos setenta, tanto as condições externas de funcionamento da escola quanto os mecanismos internos que geraram o seu movimento começaram a mudar gradualmente. Em condições ideológicas e culturais cada vez piores, a emancipação tornava-se mais difícil. Era impossível organizar as "Escolas de Verão" como anteriormente e, depois de 1973, elas cessaram e foram substituídas, de um lado, por conferências mais amplas realizadas em diferentes cidades e, de outro, por seminários que funcionavam de forma constante e que reuniam grupos mais estreitos e uniformes de especialistas. Os "Trabalhos sobre os sistemas sígnicos" foram bruscamente reduzidos de tamanho e, portanto, surgiu a necessidade de mudar o seu caráter de maneira essencial: os amplos compêndios multidisciplinares foram substituídos por edições compactas e monotemáticas (GASPÁROV, 1994, p. 293-294).

Entretanto, apesar do aparente encerramento das atividades da Escola, as suas abordagens e pesquisas continuaram a ser desenvolvidas e aprimoradas, portanto, não se trata de um ponto final em sua existência. Nos anos 1990, muitos semioticistas, ao publicarem as memórias, lançam um olhar retrospectivo sobre a semiótica soviética dos anos 1960-1970.

Como vimos, a própria Escola passa a ser abordada como um fenômeno semiótico. Serguei Nekliúdov observa ainda que o método estrutural-semiótico, desenvolvido pela Escola, deixa de ser exclusivo de um círculo estreito de pesquisadores e passa a ser "popularizado". Eis como ele descreve a situação da área dos estudos de folclore, que sempre estava entre os principais interesses da Escola, no final do século XX:

Seja dito, no entanto, que, nos anos 1980, a linha divisória entre a folclorística "estrutural" e a "tradicional" (incluindo a comparativa, a histórica, etc.) desapareceu rapidamente. Isso foi acompanhado pelo abrandamento de alguns exageros da abordagem semiótico-estrutural, de um lado e, do outro, pela popularização dos seus procedimentos, cuja eficácia ficou evidente. (NEKLIÚDOV, 2006, p. 21).

Embora a observação de Nekliúdov se refira à área da folclorística, a fusão entre o estruturalismo e a linha tradicional, ocorrida nos últimos anos da época soviética, é um traço típico tanto dos estudos literários e linguísticos, quanto semióticos. Vale observar ainda que a combinação entre o "tradicionalismo" e o "estruturalismo" é uma das características fundamentais da semiótica da cultura de lúri Lotman, sempre presente em suas obras. 
Após a dissolução da Escola, nos anos 1980, que nunca chegou a ser declarada oficialmente, mas foi observada por todos os seus participantes, Lotman continua a desenvolver as ideias formuladas pela Escola em seus trabalhos, que adquirem cada vez mais um caráter filosófico.

Ekaterina Volkova Américo é professora de Literatura e Língua Russa da Universidade Federal Fluminense. Possui bacharelado e mestrado pela Universidade Russa das Humanidades (Rússia, Moscou), mestrado e doutorado pelo Programa de Pós-Graduação em Literatura e Cultura Russa da USP. A presente pesquisa foi realizada com apoio financeiro da CAPES.

katia-v@ya.ru

\section{Referências}

GASPÁROV, B. Tártuskaia chkola 1960-kh kak semiotítcheski fenómen. (A escola de Tártu dos anos 1960 como um fenômeno semiótico). In: lu. M. Lótman i tártusko-moskóvskaia semiotítcheskaia chkola. (lu. M. Lotman e Escola semiótica de Tátru-Moscou). Moscou: Gnózis, 1994, p. 279-294, 2 vol.

IVÁNOV, Vv. Duas forças no simbolismo moderno. In: CACALIERE, A.; VÁSSIMA, E.; SILVA, N. (Orgs.). Tipologia do simbolismo nas culturas russa e ocidental. São Paulo: Humanitas, 2005. p. 197-244.

KALÍNIN, Iliá. Tártusko-moskóvskaia semiotítcheskaia chkola: semiotítcheskaia modél kultúry / kultúrnaia model semiótiki. (Escola semiótica de Tártu-Moscou: o modelo semiótica da cultura / o modelo cultural da semiótica). NLO, n. 98, 2009. Disponível em: <http://magazines.russ.ru/ nlo/2009/98/ka6.html>. Acesso em: 14 abr. 2014.

LIÉVIN, lu. Za zdoróvie Ee Velítchestva! (Pela saúde de Sua Majestade!). In: Iu. M. Lótman i tártuskomoskóvskaia semiotítcheskaia chkola. (lu. M. Lotman e Escola semiótica de Tátru-Moscou). Moscou: Gnózis, 1994, p. 309 -312, 2 vol.

LOTMAN, I. Liéktsii po struktúrnoi poétike. (Curso de poética estrutural). In: Trudý po znákovym sistiémam. (Trabalhos sobre os sistemas sígnicos), n. 1, Tártu, 1964.

. Ne-memuáry. (Não-memórias). In: Lótmanovski sbórnik. (Coletânea de Lotman). I. Moscou: OGI, 1995, p. 5-53.

MACHADO, I. Escola de Semiótica - A Experiência de Tártu-Moscou para o estudo da Cultura. São Paulo: Ateliê Editorial, 2003.

NEKLIÚDOV, S. A folclorística russa e as pesquisas semióticas estruturais. In: BERNARDINI, A. F.; PIRES FERREIRA, J. (Orgs.). Mitopoéticas: da Rússia às Américas. São Paulo: Humanitas, 2006, p. 17-28.

PIRES FERREIRA, J. Cultura é memória. In: Armadilhas da Memória. São Paulo: Ateliê Editorial, 2004, p. 69-90.

SCHNAIDERMAN, B. (Org.). Semiótica Russa. São Paulo: Editora Perspectiva, 1979 
Os escombros e o mito. A cultura e o fim da União Soviética. São Paulo: Editora Schwartcz, 1997.

TYNIÁNOV, I. Literatúrnyi fakt. (O fato literário). In: Poétika. Istória literatúry. Kinó. (Poética. História da literatura. Cinema). Moscou: Naúka, 1977, p. 255-270.

USPIÉNSKI, B. K probliéme guenézissa tártusko-moskóvskoi semiotítcheskoi chkóly. (O problema de gênese da escola semiótica de Tártu-Moscou). In: lu. M. Lótman i tártusko-moskóvskaia semiotítcheskaia chkola. (lu. M. Lotman e Escola semiótica de Tátru-Moscou). Moscou: Gnozis, 1994, p. 265-278, 2 vol.

USPIÉNSKI, V. Progúlki s Lótmanom i vtorítchnoe modelírovanie. (Os passeios com Lotman e a modelação secundária). In: Lótmanovski sbórnik. (Coletânea de Lotman). I. Moscou: OGl, 1995, p. 99-127. 